\title{
Energy Policies and Research/Development Trends in the USA
}

\author{
Hulya Kirkici ${ }^{\dagger}$ \\ Department of Electrical and Computer Engineering, Auburn University, Auburn, AL 36849-5201, USA
}

\author{
Bruce Bernstein \\ Bruce S. Bernstein Consulting, LLC., Rockville, MD 20854, USA
}

Received July 21, 2010; Accepted August 10, 2010

\begin{abstract}
As the world population increases and technology advances, the energy consumption and need for more energy increase. Communities and governments regularly address these needs and set policies for future energy generation and uses. This paper reviews current energy policies of the USA and the current trends in research and development efforts, for sustainable and renewable energy sources. Furthermore, the recent topic of IEEE's Smart Grid initiatives is discussed, and its role in the dielectrics and electrical insulation research is presented.
\end{abstract}

Keywords: Renewable energy, Energy policies, Dielectrics, Insulation systems, Smart grid

\section{INTRODUCTION}

By definition, sustainable energy is the provision of energy that meets the needs of the present without compromising the ability of future generations to meet their needs. This usually means the energy produced from "traditional sources" such as fossil fuel or the sources that are not depleted over time such as nuclear power. In addition to sustainable energy, as a society we also depend on and use energy from renewable energy sources, such as solar power, wind power, etc. On the other hand, the use of the energy from these sources is not as wide spread as desired because of the inefficient energy conversion of the current technologies available to us. Regardless of how the energy is generated and from what sources, the uses of these and production, distribution to consumers are usually determined by governing bodies. In America, the energy needs of the nation and the policies are primarily set by the federal government, state government, and other local public entities. These policies are set to address the issues of energy production, distribution, and consumption: examples include building codes, gas mileage standards, and tax incentives for both renewable and non-renewable energy. In addition to the government policies, other non-profit entities also

${ }^{\dagger}$ Author to whom all correspondence should be addressed:
E-mail: hulya.kirkici@ieee.org contribute in the development of the policies and public awareness of the generation and efficient uses of energy. One such organization is the Institute of Electrical and Electronics Engineers (IEEE), the largest professional society; home to the electrical and electronics engineering related professionals in the world. A recent initiative by the IEEE is the smart-grid and its global role in energy. Although the definition of Smart Grid differs from "region" to "region" its aim is to have a global impact in efficient use of energy and use of the advanced technologies in the generation, distribution, and consumption of energy. Expected results are the development of new technologies such as bio-fuels/solar energy/wind energy; energy efficient living; electric-cars; energy storage, and others. On the other hand, materials issues and stresses on Smart Grid and other applications are some of the issues that need addressing.

\section{WORLD ENERGY CONSUPTION AND ENERGY NEEDS}

According to the data given in reference [1], the worldwide energy consumption in 2008 was about $474 \times 10^{18}$ Joules. The breakdown of world's energy consumption according to the sources for the last 25 years is given in Fig. 1 [2]. From this figure 
Table 1. USA energy consumption and sources [3].

\begin{tabular}{llll}
\hline \multirow{2}{*}{ Fuel type } & \multicolumn{3}{c}{ Average power in terawatts } \\
\cline { 2 - 4 } & 1980 & 2004 & 2006 \\
\hline Oil & 4.38 & 5.58 & 5.74 \\
Natural gas & 1.80 & 3.45 & 3.61 \\
Coal & 2.34 & 3.87 & 4.27 \\
Hydroelectric & 0.559 & 0.933 & 0.895 \\
Nuclear power & 0.253 & 0.914 & 0.929 \\
Geothermal, wind, solar & 0.016 & 0.133 & 0.158 \\
Total & 9.48 & 15.0 & 15.8 \\
\hline
\end{tabular}

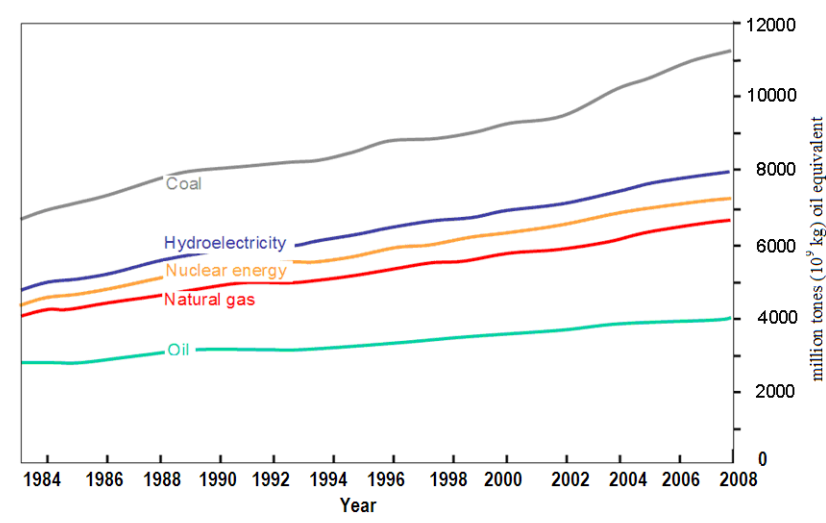

Fig. 1. World energy consumption growth given in million tones oil equivalent plotted as a function of years [2].

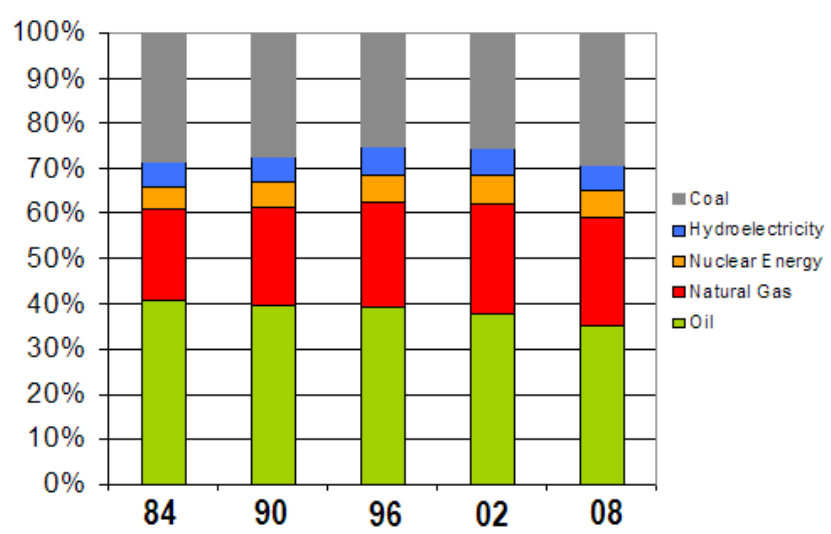

Fig. 2. World energy consumption percentages shown for every 6 years, starting 1984 .

one can estimate that in 2008 , over $90 \%$ of the energy consumption was from fossil sources world wide. Furthermore, while oil remains the world's dominant fuel source, as a percentage, oil consumption steadily has been decreasing while coal and natural gas consumption has been increasing for the last 10 to 12 years (Fig. 2). One thing clear from this data is that the energy from renewable sources is not a major player in the world's energy consumption.

Table 1 shows a scenario in the USA which is not much different than the world energy consumption [3]. According to the data in Table 1, a large portion of the energy, over $85 \%$ of the total, is generated from fossil (oil, natural gas, and coal) sources. This is a very large percentage compared to only about $12 \%$ of the energy is generated from renewable sources, such as hydro and nuclear. Among this, only about $1 \%$ of the energy is generated from geothermal, solar, and wind power. If we look at world's energy consumption by region, we see a similar trend, with a few variations: the Middle-East region which consumes energy mostly from oil and natural gas, while the Asia Pacific region consumes it from oil and coal. On the other hand, only Southand Central-American regions are where the largest percentage of hydroelectric consumption is recorded (compared to other regions) [4]. What is clear from all this data is that energy consumption from renewable sources is not a major factor.

Although, many countries develop and offer programs to stimulate the use of energy from renewable sources, due to many factors such as efficient energy conversion, cost of the production, etc. this sector has not been making an impact in people's daily lives. There are more choices available, but it is not clear which one is the best. Currently, most sectors supplement current energy sources (mainly fossil) with cleaner "greener" sources (e.g. solar and wind) of energy, offering "green" pricing to residential customers. For example, over all, only $3 \%$ of household in the USA participate in such a program and higher income level household regions are more likely to adopt 'green" energy programs [5]. Furthermore, younger people are more likely to adopt (14\% for ages between 18 and 34; $39 \%$ for ages between 35 and 54) and politically, liberals and moderates are more likely to adopt the "green" programs than the others [5]. Figure 3 shows the green energy participation in the USA by regions. As seen, East and West Cost states participate in these programs than the nid- and nort east states. The data in [5] also indicates that over $35 \%$ of the people who adopt the "green" energy program in the USA prefer solar energy, while over $30 \%$ do not have a preference. Among these, the primary motivation for choosing "green" energy programs is to cut cost and save money. This clearly indicates that the main reason for renewable energy consumption by consumers is economical. That means, if the industry and the governments want "green" energy to be successful, they should consider investing in research and development for the new technologies involving efficient energy conversion that are cost effective. In fact some research programs, sponsored by the USA government are being announced recently, and some other initiatives are being taken to address the issues in hand.

\section{ENERGY POLICY OF USA}

The policies in the USA are determined by federal, state, and local public entities which address issues of energy production, distribution, and consumption, such as building codes, gas mileage standards, tax incentives for both renewable and nonrenewable energy. The latest USA energy policy that has passed at the federal level is: Energy Independence and Security Act of 2007 (enrolled as agreed to or passed by both House and Senate) $[6,7]$. Some of the policies can be summarized as follows:

1. Corporate Average Fuel Economy (CAFE). This is policy imposes a gas usage per mile on the vehicles. It states that each vehicle manufactured and in use will have a target of 35 miles per gallon for the combined fleet of cars and light trucks by model year 2020 .

2. Renewable Fuels Standard (RFS). This is a modified standard that starts at 9.0 billion gallons of fuel to be from renewable sources in 2008 and rises to 36 billion gallons by 2022.

3. Energy Efficiency Equipment Standards. This is a policy that includes a variety of new standards for lighting and for residential and commercial appliance equipment, such as high efficient light bulbs (e.g. halogen or LED based) and high efficient appliances (e.g. refrigerators, washing machines).

4. Repeal of Oil and Gas Tax Incentives. This is a policy that includes repeal of two tax subsidies in order to offset the estimated 


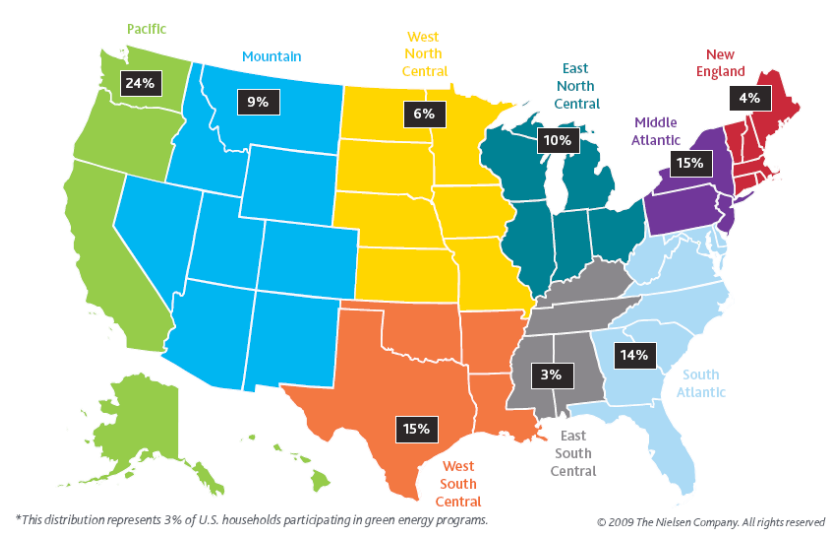

Fig. 3. Green energy participation in the USA by regions [5].

cost to implement the CAFE provision. Because it is expected that the cost of such vehicles may be higher, and consumers may not be encouraged to purchase such vehicles, with this tax incentive, these costs are off-set.

The state based policies usually follow the federal policies and they include the same or modified versions of the federal policies. As an example, incentives for renewable and efficient energy in the State of Alabama can be summarized as follows. The mission of the Energy Division is to increase energyefficiency, reduce energy consumption, and promote market acceptance and deployment of energy-efficient and renewableenergy technologies [8]. For example, (a) personal deduction for use of efficient energy usage, (b) production incentive (from utility partners) to Commercial, Residential (i.e. Photovoltaics, Landfill Gas, Wind, Biomass, etc.), (c) State Grant Program (such as Biomass Energy Program), (d) State Rebate Program Alabama (Residential Energy-Efficient Appliance Rebate Program), (e) Utility Loan Program (e.g. Alabama Power Company's Residential Heat Pump and Weatherization Loan Programs, and others) are some of the incentives available to the residents of the State of Alabama.

\section{RESEARCH AND DEVELOPMENT PROJECTS}

Based on the policies set by the governments, the research grants to educational institutions are also becoming available from government sources [9]. Universities and other educational institutions have been establishing "Energy" related "Curriculum" as reported [10] at the undergraduate or graduate levels. Furthermore, US Department of Energy projects are also available to the national laboratories. For example, recently it was reported that Oak Ridge National Laboratory will be the headquarters for the first of three energy innovation hubs planned by the US Department of Energy. In these multi-million dollars projects, a team of scientists and engineers from universities, industry and other national labs will be collaborating to make significant leaps forward in new nuclear reactor design and engineering, while another will be looking at developing fuels from sunlight in an economical way and conducting research in ways to make buildings more energy efficient.

\section{SMART GRID AND OTHER POLICY RECOMMENDATIONS}

IEEE is a "public" organization that studies public issues, de-

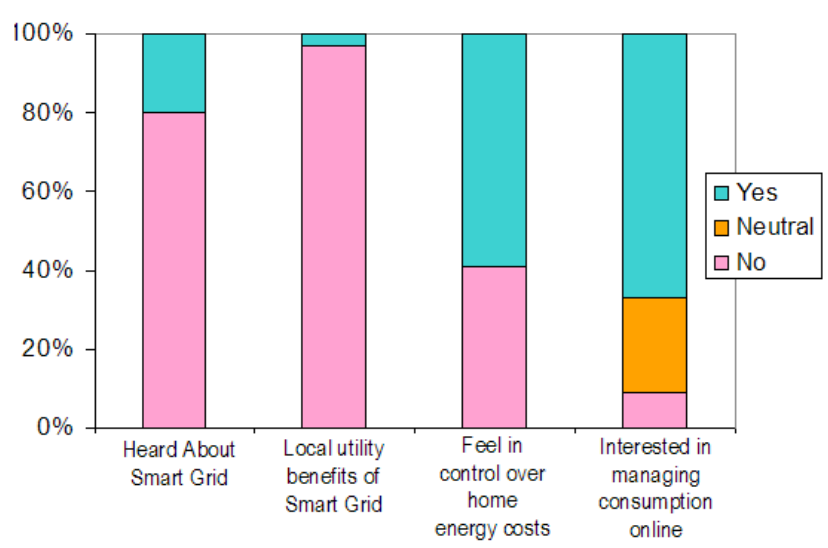

Fig. 4. Statistical data of consumer knowledge and interest in Smart Grid.

velops standards, and recommends policies in technology related areas. One such current interest and initiative is the "Smart Grid." Smart Grid has been a "buzz" word of the last few years, but now there are many projects utilizing the ideas behind the Smart Grid-a new technology to offer benefits to the consumers in energy and power areas. It usually means different things to many people; the definition varies from country to country, region to region, and discipline to discipline. However, one definition many can agree on is: "a smart grid delivers electricity from suppliers to consumers using two-way digital technology to control appliances at consumers' homes to save energy, reduce cost and increase reliability and transparency." For the consumers, it is expected to offer different pricing opportunities and ability to manage energy consumption online. This is basically a project undertaken by a group of industrial and IEEE partners to transforming the current "Network" into a Smart Grid [11]. That means: add intelligence to the existing grid, apply renewable generation resources, implement improved transmission and distribution, improved home to grid, industry to grid, building to grid technologies, integrate renewable and distributed energy resources, add large scale energy storage capability and increase energy efficiency. In fact these are challenging topics and some of them may not be realized. These issues demand major changes in power system operating philosophy, and the transition must be evolutionary. Furthermore, since many organizations are involved in the "grid," these organizations must properly manage the change involved in adopting emerging technologies and uniform standards.

Statistical data of consumer awareness of smart-grid shows that about $80 \%$ of the public have not heard about it, over $95 \%$ do not have knowledge and interest in local utility shared benefits of smart grid (Fig. 4) [5]. The current Smart Grid objectives at IEEE are positioning IEEE as the "go to" resource for information and collaboration on the Smart Grid, leverage its strong technical foundations to advance technology and facilitate successful Smart Grid deployments throughout the World by developing standards, sharing best practices, publishing developments and providing related educational offerings. Ideally, the work should be described as "end-to-end network" and the grid of 2030 should be a machine-to-machine world, extending from generation to transmission to distribution and all the way down to the devices in homes, offices and factories. In fact some of these are already in place and can be found on the IEEE website [11].

One example to the application of "Smart Grid" perhaps is the case of charging stations for plug-in hybrid-electric vehicles (PHEV). One of the policies listed above calls for the use of green energy. Currently major car-maker companies are also producing PHEV and some of the concerns they have with these vehicles in- 


\section{Coulomb Technologies ChargePoint Network}

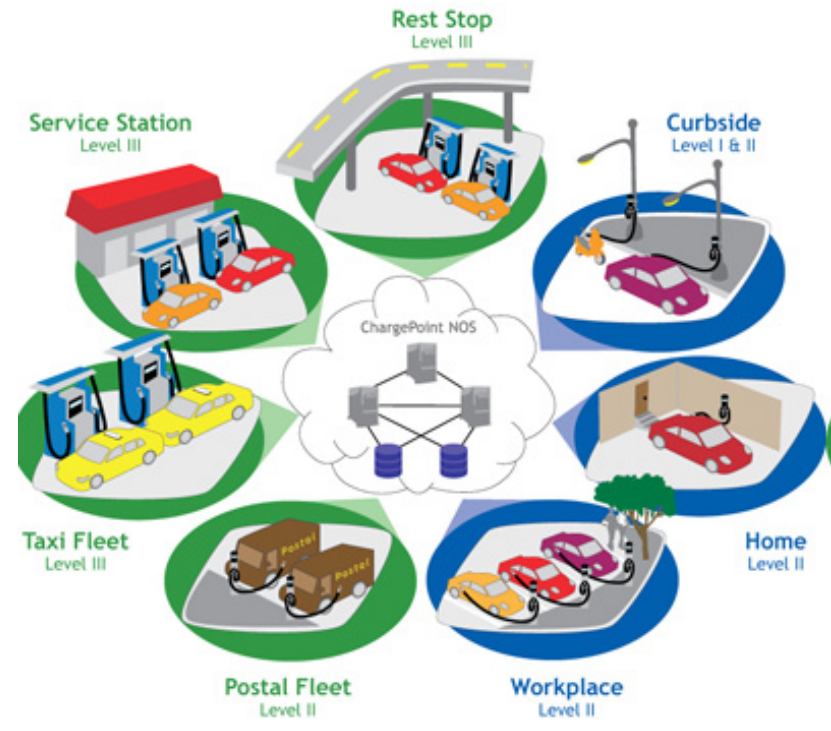

Fig. 5. Schematic representation of Coulomb Technologies' ChargePoint ${ }^{\circledR}$ Network [12].

clude: availability of the market for these vehicles, battery range that is acceptable for the consumers, and style of the cars that consumers would be pleased with and that can also support the technology. While these are the automakers' concerns, utilities also have similar concerns, such as the market for these vehicles in the "service" territory, changing station locations for these vehicles, impact on the electricity load and the grid, and others.

One US company [12] has already been addressing some of the above questions by providing vehicle charging stations for the PHEV with an open system driver network. A schematic view of the operation is shown in Fig. 5. Their product, ChargePoint network provides multiple web-based portals for hosts, fleet managers, drivers, and utilities. Networked charging stations are ranging in capability from $120 \mathrm{~V}$ to $240 \mathrm{~V} \mathrm{AC}$ and charging and up to $500 \mathrm{~V}$ DC voltage. The software is offered on-demand and are accessible anywhere there is an Internet connection from your workstation or mobile device. Software services help you to locate charging stations along your commute route, perform demand side management, track the performance of your EV fleet, or establish pricing for access to your charging stations. Network services ensure the charging stations remain operational, that consumers are assisted by friendly support representatives when needed, and any revenues collected from the charging stations are automatically transferred to "suppliers" bank account.

Although the technology is advancing in terms of renewable energy generation and green energy uses, there are still issues that need addressing. For example wind speed and control of is one of the challenges of the wind energy generation. As high efficiency is achieved when the wind speed is constant for long durations, once it stops the control of the generator and the unexpected cut-off energy is still a problem. In the case of solar energy, the cost of the overall system, conversion of DC to AC efficiency, and the storage (from day-time while generating energy to at night-time using stored energy) are issues that need addressing. Furthermore, currently most of these systems operate in "stand" alone mode (not part of the overall nationalgrid). Integration of these renewable energy sources into the "Smart Grid" is expected; however, the issues they will bring with them are not clearly defined and the impacts of these on the grid are not yet well know.

\section{MATERIAL ISSUES AND STRESS ON THE GRID}

Our current transmission system for electricity (the electrical grid) in the USA was built largely in the 1960s or before, and is in need of a major upgrade with new technologies to eliminate blackouts and other disturbances that occur when we cannot anticipate, detect, respond to and correct problems in the grid quickly. This is also true for distribution systems and generation technologies. The smart grid is a modernized, self-monitoring system, based on industry-wide standards, crossing international borders and participating in wholesale energy trading, providing a stable, secure, efficient and environmentally sustainable network.

The 'challenge' for dielectrics and electrical insulation to be visible in the Smart Grid initiatives is to determine exactly how to 'fit in'. The 'Smart Grid 'charge forward is focusing on overview issues, i.e. more visible and technology driven, whereas dielectrics and electrical insulation issues are more fundamental and specialize in localized problems (relative to the grid overview issues). For example, the dielectrics and electrical insulation community is focused around electric insulation concerns and dielectric properties of materials under stresses conditions from both a research and application perspective. Such insulation or dielectric will definitely be employed in equipment components incorporated into the smart grid. Indeed some present insulation components parameters are currently employed in the conventional grid and some new insulation technologies will certainly be required to make the Smart Grid functional and reliable. In seeking to upgrade the grid, insulation will be a key component for some parts, but this has not been clearly defined from the overview position. Indeed the technology suggested for incorporation into the smart grid may be "incomplete."

To focus on electrical insulation matters, one has to evaluate what the issues are and where hardware is involved. It is necessary to apply knowledge of the hardware issues and evaluate whether the insulation issues in providing Smart Grid reliability are understood and whether there are unsolved problems requiring further research and development. Therefore, one needs to determine the state-of-the-art technology and the advanced materials and their applicability in the insulation systems.

The technology presently known in the area of diagnostic test procedures and sensors, and how these can be applied to equipment being employed are another contribution to the Smart Grid by the dielectrics and electrical insulation community. For example, on-line monitoring represents a significant opportunity.

One other issue not many are addressing is the insulation integrity under high frequency harmonics. As known, most converters in advanced power systems use high power solid-state devices such as gate turn-off thyristors (GTO) and/or insulated gate bipolar transistors (IGBT) with high switching frequencies. These switches can have frequencies typically between 1 to $2 \mathrm{kHz}$ or even higher. Fast switching of these high-power electronic devices results in generating steep front voltages containing high-frequency harmonics. Because, the Smart Grid will require a significant amount of switching operation to allow load changes, this is expected to result in varying thermal stresses [13]. Furthermore, it is known that the breakdown strength of dielectric materials at higher frequencies than $1 \mathrm{kHz}$ is usually lower than its dc breakdown strength [14]. Therefore, further stresses in addition to thermal and field, are exacted. This last issue, in fact has not been address by many researchers as yet.

\section{CONCLUSIONS}

In the USA, the policies are placed at the federal and state 
levels with respect to the green energy generation and uses of it. Consumers are more aware of the renewable versus fossil energy issues; however, the percentage of people willing to make the switch to renewable energy sources still seems to be relatively low. This may be related to the cost and its availability to the consumer. Under the current energy policy, realization of the "grid" age and new initiatives for the Smart Grid is in place. Though there are many studies, educational activities, and publications available in this topic, there are still unanswered questions surrounding the Smart Grid. These mainly include the technology versus consumer benefits and uses. Spin-off efforts to network energy/consumption via internet are positive developments, since most households in the USA have access to the internet and are users of it. There are research and development efforts at the university and Federal level for "renewable" and "sustainable" energy (i.e. solar, bio, wind). One major issue has not seen much attention, but has a very important role in the new technologies of smart grid is the materials aging, monitoring, sensing in the power systems. The authors believe that there is still much work to do to completely understand the issues posed by energy demand in general.

\section{ACKNOWLEDGMENTS}

Author Hulya Kirkici acknowledges the invitation by KIEEME to present this work at its annual Conference in the summer of 2010.

\section{REFERENCES}

[1] "BP Statistical review of world energy June 2006" (http:/ / www. bp. com/ liveassets/ bp_internet/globalbp/globalbp_ uk_english/reports_and_publications/ statistical_energy_re-
view_2006/STAGING/ local_assets/downloads/spreadsheets/ statistical_review_full_report_workbook_2006. xls) (XLS). British Petroleum. June 2006. . Retrieved 2007-04-03. and "BP Statistical Review of World Energy June 2010" retrieved, October 7, 2010, from http://www.bp.com/sectiongenericarticle.do?categ oryId $=9033088 \&$ contentId $=7060602$

[2] World Consumption of Primary Energy by Energy Type and Selected Country Groups-Table 18; retrieved on October 7, 2010, from (http:/ / www. eia. doe. gov/ pub/ international/ iealf/ table18. xls) December 31, 2008 Microsoft Excel file format]];

[3] "international Energy Outlook 2010" Retrieved on October 7, 2010 from http://www.eia.doe.gov/oiaf/ieo/ pdf/0484\%282010\%29.pdf and " U. S. Energy Consumption by Energy Source " retrieved October 72010 from http://www.eia. doe.gov/cneaf/solar.renewables/page/trends/table1.html

[4] "BP Statistical Review of World Energy June 2010" retrieved on October 7, 2010 from http://www.bp.com/sectiongenericarticle.do? categoryId $=9033088 \&$ contentId $=7060602$

[5] Neilson Report, October 2009 [www.neilsen.com]

[6] [http://www.thomas.gov/cgi-bin/query/z?c110:H.R.6.ENR:]

[7] [http://frwebgate.access.gpo.gov/cgi-bin/getdoc. cgi?dbname=110_cong_bills\&docid=f:h6enr.txt.pdf]

[8] [http://www.dsireusa.org/] [http://adeca.alabama.gov/Energy/] [http://www.dsireusa.org/incentives/index.cfm?Current PageID $=1 \&$ State $=$ AL\&RE $=1 \& E E=1]$

[9] NSF Research Grants [http://www.nsf.gov/funding/pgm summ.jsp?pims_id=501026]

[10] [Sustainability Movement "Transforming" Curricula Of US Engineering Colleges, U.S. News \& World Report, March 15, 2010]

[11] [http://drop.io/IEEESmartGrid]

[12] [ww.coulombtech.com]

[13] S.H. Jayaram, unpublished, email correspondence with the authors, June 2010

[14] H. Kirkici, M. Serkan, and K. Koppisetty, IEEE Trans. Dielectr. Electr. Insul. 14, 790 (2007) [DOI: 10.1109/TDEI.2007.4286508]. 